\title{
公差が指示された組立品の配位空間を用いた 位置姿勢の曖昧さの解析*
}

\author{
乾 正 知** 金 田光 広*** \\ Configuration Space Based Analysis of Position Uncertainties of \\ Toleranced Parts in an Assembly \\ Masatomo INUI and Mitsuhiro KANEDA
}

\begin{abstract}
A new method for analyzing position uncertainties of two parts in an assembly is proposed if certain shape deviations of individual parts are allowed by tolerances. Assembling of a mechanical product is usually achieved by mating some face pairs of the component parts. Realization of the proper surface contact is important for precisely achieving the machine function. Based on this concept, the authors derive three necessary conditions on the configuration of two non-nominal parts in an assembly, which are non-penetration condition, contacting condition of mating faces, and optimization condition concerning their assembling method. Proposed method achieves the tolerance analysis by computing a variation bound of the configuration of two toleranced parts if some non-nominal parts allowed by tolerances satisfy the necessary conditions. Since rotations are linearized by assuming small positional variations, the conditions can be described by a set of linear inequalities on configuration parameters of the parts. The variation bound thus becomes a union of some polytopes in the configuration space. An experimental program for computing the variation bound is implemented and demonstrated.
\end{abstract}

Key words: tolerance analysis, configuration space, tolerance modeling

\section{1.はじめに}

機械部品の形状には，加工に起因する誤差が必ず含まれている. 形状誤差は，製品の挙動に望ましくない影䇾を与える. そこで設計 者は, 公差を用いて個々の部品の許容できる誤差の範囲を指定し， 挙動の変動を管理する. 公差方式には, 寸法值の許容符囲を指示す る寸法公差と, 許容できる誤差の節囲を表す幾何的な領域（=公差 域）を指示する幾何公差の二つがあるが，ここではより精密な誤差 管理が可能な幾何公差のみを考える，敞しい公差を指定すれば，機 能のより正確な実現が可能となるが, 部品の加工が困難になり憋造 コストが上昇してしまう. 現状では, 過去の設計事例や経験的な知 識を参考に試行錯誤を繰り返し，機能的にも経济的にも妥当な公差 を決定していることが多い.

このような公差設計を支援するために, 公差に起因する挙動の変 動を計算機を用いて評価する, 公差解析とよばれる技術が研究され ている. 特に本論文では, 公差が指示された組立品における, 部品 間の相対的な位置姿勢の暧陎さの解析を考える. Turnerらは, 公 差をともなう部品の位置決めを, 最適化問題として定式化し解く手 法を提案している 8）10)。この手法では, 立体モデルの面の微小 移動により形状誤差を表現するので, いわゆる形状偏差の影製が評 価できない. Flemingは, 公差が指示された 2 部品が, 安定した 組付け状態を保ちつつ実現できる最も極端な位置姿勢を, 幾つかの 典型的な部品の組合せについて解析し，それを不等式制約として評 価する手法を提案している 1 ).

われわれは, 従来の手法とは異なり, 解析可能な部品形状や誤差 のタイプを制限しない，新しい公差解析手法を開発した 2) 3).こ の手法では, 公差域が指示された 2 個の部品モデルの組立てと, 公 差域が許容する誤差を含む実部品モデの組立てを考える. 公差域 が指示された側の部品モデルを動かすと, モデルに付随する公差域

\footnotetext{
*原稿受付平成 9 年 1 月 29 日

**正会員茨城大学工学部 (日立市中成沢町 4-12-1)

***学生会員茨城大学工学部
}

が移動するので，許容誤差を含む実部品モテルの位置姿勢も変化す る. 機珹暼品の組立て作業は，対偶を介して部品を接続する作業と見 なせる．そこで実部品モデルが適切な対偶関係を実現するように， 公差域が指示された側の部品モデルを位置決めすることを考える.

公差域は多様な誤差を許容する.したがって実部品モデルの誤差 の状態に応じて，公差域をともなう部品モテルの位置決めされた状 態も変化する. われわれの手法は，この変化の範囲を算出すること で，公差が許容する組立品の位置姿勢の暖昧さを解析する．多くの 機械彆品の組立ては，部品や部分組立品の逐次的な組付け作業に分 解できる. 組み付けられた 2 部品の相対的な位置姿勢の暧昧さが解 析できれば，逐次的な租付けプロセスを表すグラフ構造に基づいて 解析結果を伝播させることで，3 個以上の部品からなる組立品も解 析できる 1$)$.

論文 2) 3) に報告した手法は，離散的に表現された配位空間を 用いて解析をおこなうため，処理時間と必要な記憶容量に問題が あった．公差に起因する位㯰姿勢の変動は，ごく微小と考えられ る.この性質を利用して，組立てられた二つの多面体部品の相対的 な位置姿勢の变動筑囲を高速に算出するアルゴリズムを開発したの で報告する． 2 章では幾つかの数学的な準備をおこなう．次に 3 章 でわれわれの公差解析理論を简単に紹介した後，4章で開発した公 差解析アルゴリズムを説明する．最後に 5 章で，本手法を用いて解 析をおこなった例を紹介する.

\section{2. 蔡流}

\section{議論を進めるために必要な定義を示す．}

\section{1 微小变位ベクトル}

組立てられた 2 個の理想的な形状の部品モデル $\mathcal{M}_{n}$ と $\mathcal{B}_{n}$ を考 える. $\mathcal{M}_{n}$ と $\mathcal{B}_{n}$ のそれぞれに，その位置姿勢を代表する座標系 $\mathcal{F}_{\mathcal{M}_{n}}$ と $\mathcal{F}_{\mathcal{B}_{n}}$ を与える. すると, $\mathcal{M}_{n}$ と $\mathcal{B}_{n}$ の相対的な位置姿 勢（=配位） は, 座標系 $\mathcal{F}_{\mathcal{B}_{n}}$ における $\mathcal{F}_{\mathcal{M}_{n}}$ の位置を表す 6 個 のパラメータ $\mathbf{q}_{n}=\left[x, y, z, \theta_{x}, \theta_{y}, \theta_{z}\right]$ により表現できる. $\mathbf{q}_{n}$ は, 無誤差の部品を組立てた場合の理想的な配位を表す。これは機 


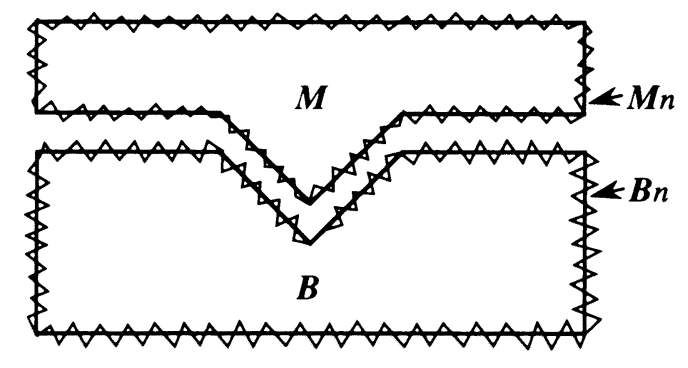

Fig.1 Section views of assembled non-nominal solids $\mathcal{M}$ and $\mathcal{B}$, and their corresponding nominal solids $\mathcal{M}_{n}$ and $\mathcal{B}_{n}$

械図面などから容易に読みとれる.

形状誤差を持つ実部品のモデル $\mathcal{M}$ と $\mathcal{B}$ は， $\mathcal{M}_{n}$ と $\mathcal{B}_{n}$ の表面 に微小な凹凸が生じたものと見なせる．以後 $\mathcal{M}_{n}$ と $\mathcal{B}_{n}$ を理想立 体， $\mathcal{M}$ と $\mathcal{B}$ を実立体とよぶ（図 1参照）。定義から，理想立体 $\mathcal{M}_{n}$ と $\mathcal{B}_{n}$ の配位と, 実立体 $\mathcal{M}$ と $\mathcal{B}$ の配位は常に一致する. $\mathcal{M}$ とB を組立てたとき，その配位 $\mathbf{q}$ は形状誤差の影㯁で，理想 的な配位 $\mathbf{q}_{n}$ から微小量ずれている。 そこで微小な変位を表すべク トル $\delta \mathbf{q}=\left[\delta x, \delta y, \delta z, \delta \theta_{x}, \delta \theta_{y}, \delta \theta_{z}\right]$ を導入し, 組立てられた実 立体の配位を $\mathbf{q}=\mathbf{q}_{n}+\delta \mathbf{q}$ と表すことにする. 以下の議論では， 理想的な配位から $\delta \mathbf{q}$ 変位した立体 $\mathcal{S}$ を $\mathcal{S}(\delta \mathbf{q})$ と書く.

\section{2 面の公差モデル}

幾何公差は, 許容誤差の節囲を表す空間的な領域を, データム や理想的な形状に基づいて定義し誤差を管理する 4)。 Requicha は，立体モデリングの手法を用いて，幾何公差をより一般的な形で 定式化した 7 )。本論文では，この研究に基づいて，部品表面の公 差モデルを以下のように定義する.

理想立体 $\mathcal{M}_{n}$ の表面 $\partial \mathcal{M}_{n}$ を，幾つかの理想的な形状の 曲面要素 (これを理想曲面とよぶ) $F_{\mathcal{M i}}$ へ分割する. ただし $\bigcup_{i} F_{\mathcal{M} i}=\partial \mathcal{M}_{n}$ を满たすものとする．そして各理想曲面 $F_{\mathcal{M} i}$ に，以下の条件を満足する面の公差域 $\mathcal{T}\left(F_{\mathcal{M i}}\right)$ を定義する;

(1) 面の公差域 $\mathcal{T}\left(F_{\mathcal{M}_{2}}\right)$ の位置姿勢は， $\mathcal{M}_{n}$ の座標系に固 定されている.

（2）理想曲面は対応する面の公差域に含まれる，すなわち $F_{\mathcal{M} i} \subseteq \mathcal{T}\left(F_{\mathcal{M} i}\right)$ が成り立つ.

（3）面の公差域は有界である. 現行の幾何公差方式では, 多く の公差域は無限の広さをもつ、本研究では, 論文 1)に基づい

て、無䭾な領域を削除した有界な公差域を考える.

$\mathcal{B}_{n}$ の理想曲面 $F_{\mathcal{B} j}$ にも，同様の手順で公差域 $\mathcal{T}\left(F_{\mathcal{B} j}\right)$ を定義す ろ.

次に実立体 $\mathcal{M}$ の表面を, 以下の条件を満たす曲面要素(これを 実曲面とよぶ） $G_{\mathcal{M i}}$ の集合へ分割する。

(1) $\bigcup_{i} G_{\mathcal{M} i}=\partial \mathcal{M}$

(2) 理想曲面 $F_{\mathcal{M} \imath}$ と実曲面 $G_{\mathcal{M} 2}$ の間に, 1 対 1 の対応付け が可能.

$\mathcal{B}$ の表面も同様の手順で分割し実曲面 $G_{\mathcal{B} j}$ を得る. そして実曲面 が，对応する理想曲面に付随する公差域に包含されるとき，その実 曲面は公差を満たすと判定する．したがって実曲面 $G_{\mathcal{M} i} や G_{\mathcal{B} j}$ は，以下の条件を満足する必要がある（図2参照）。

$$
\begin{aligned}
G_{\mathcal{M} \imath} & \subseteq \mathcal{T}\left(F_{\mathcal{M}_{\imath}}\right) \\
G_{\mathcal{B}_{\mathfrak{\jmath}}} & \subseteq \mathcal{T}\left(F_{\mathcal{B}_{\jmath}}\right)
\end{aligned}
$$

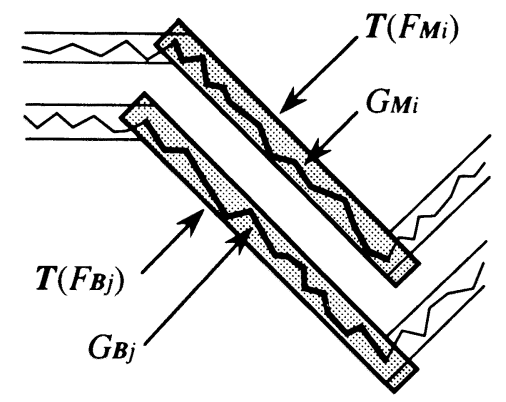

Fig.2 Face tolerance zones $\mathcal{T}\left(F_{\mathcal{M}_{i}}\right)$ and $\mathcal{T}\left(F_{\mathcal{B}_{j}}\right)$ and nonnominal surface elements $G_{\mathcal{M}_{i}}$ and $G_{\mathcal{B} j}$ with allowable deviations

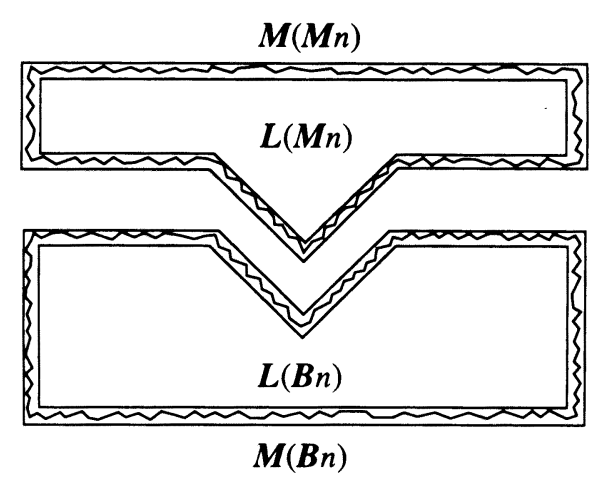

Fig.3 Spatial relationships between the maximum-material solids $\mathcal{M}\left(\mathcal{M}_{n}\right)$ and $\mathcal{M}\left(\mathcal{B}_{n}\right)$, least-material solids $\mathcal{L}\left(\mathcal{M}_{n}\right)$ and $\mathcal{L}\left(\mathcal{B}_{n}\right)$, and non-nominal solids $\mathcal{M}$ and $\mathcal{B}$ with allowable deviations

\section{3 立体の公差モデル}

理想立体の面に指示された公差域に基づいて, 公差の許容する最 大の立体（これを最大実体状態の立体とよぶ）と最小の立体（最小 実体状態の立体) が定義できる. $\mathcal{M}\left(\mathcal{M}_{n}\right)$ と $\mathcal{L}\left(\mathcal{M}_{n}\right)$ を, それ ぞれ $\mathcal{M}_{n}$ に指示された公差が許容する最大実体状態と最小実体状 態の立体とする. 同様の手順で, $\mathcal{B}_{n}$ に関する最大実体状態の立体 $\mathcal{M}\left(\mathcal{B}_{n}\right)$ と最小実体状態の立体 $\mathcal{L}\left(\mathcal{B}_{n}\right)$ を定義する.

公差の許容する実立体 $\mathcal{M}$ と $\mathcal{B}$ は, 最大実体状態の立体の内部 に含まれ，最小実体状態の立体を内部に含む．したがって以下の空 間的な制約を満たす（図3参照）；

$$
\begin{gathered}
\mathcal{M}\left(\mathcal{M}_{n}\right) \supseteq \mathcal{M} \supseteq \mathcal{L}\left(\mathcal{M}_{n}\right) \\
\mathcal{M}\left(\mathcal{B}_{n}\right) \supseteq \mathcal{B} \supseteq \mathcal{L}\left(\mathcal{B}_{n}\right)
\end{gathered}
$$

\section{3. 公差解析理战}

われわれの公差解析理論 3)を概説する.

\section{1 実立体の粗立て条件}

2 部品の組立て作業は, 「部品間の対偶関係を実現しつつ, でき るだけ望ましい位置姿勢に部品を配置する作業」と定式化できる. したがって, 実立体 $\mathcal{M}$ と $\mathcal{B}$ の組立てられた状態を表す変位べク トル $\delta \mathbf{q}$ は，以下に示す三つの条件を満たす必要がある.

非相貫条件： 組立てられた二つの実立体は，互いに他方の内部

へ食い込むことはない.したがって $\delta \mathbf{q}$ は, 条件

$$
i(\mathcal{M}(\delta \mathbf{q})) \cap i(\mathcal{B})=\emptyset
$$


を満たす．ただし $i(\mathcal{S})$ は立体 $\mathcal{S}$ の内部を表す。

接触条件： 対偶は部品間の面接触の組と考えられる. 非相貫条 件を满たす 2 立体の表面が点を共有していれば，これらは何ら かの形で接触している. したがって対偶を構成する $k$ 個の実曲 面の組 $\left\{G_{\mathcal{M i}}(\delta \mathbf{q}), G_{\mathcal{B} i}\right\}, i \in[1, k]$ が面接触を実現するため には， $\delta \mathbf{q}$ は以下の条件を満足する必要がある.

$$
\forall i \in[1, k], G_{\mathcal{M} i}(\delta \mathbf{q}) \cap G_{\mathcal{B} i} \neq \emptyset
$$

最適化条件： 組立てられた 2 部品は,「できるだけ密着する」 などの，望ましい組付け状態に関する条件を最適に満たす必要

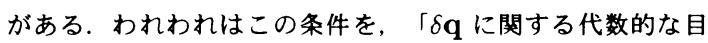
的関数 $f(\delta \mathbf{q})$ を最小化する」と定式化する. $\delta \mathbf{q}$ は微小なの で, 2 次以上の項を無視することで $f(\delta \mathbf{q})$ を線形化できる. 本論文ではこのような目的関数は与えられているものとし，そ の定義法については議論しない

\section{2 理想立体の変位ベクトルの满たすべき条件}

定義により，理想立体と実立体の配位は常に一致するので，理想 立体を動かすことで実立体の位置姿勢を変更できる，そこで公差が 許容する実立体 $\mathcal{M}$ と $\mathcal{B}$ が適切な組立てを実現するように，公差 域をともなう理想立体 $\mathcal{M}_{n}$ と $\mathcal{B}_{n}$ の配位を，理想的な組立て状態 から $\delta \mathbf{q}$ だけ動かすことを考える. $\mathcal{M}$ とB が非相貫条件，接触条 件，最適化条件を満たすためには， $\delta \mathbf{q}$ は以下に示す三つの条件を 满たす必要がある.

条件 $1 \mathcal{M}$ と $\mathcal{B}$ が非相貫条件を満たすためには， $\delta q$ は以下のよう に定義される変位ベクトルの部分空間 $\mathcal{S}_{n i}$ に含まれる必要がある ;

$$
\mathcal{S}_{n i}=\left\{\delta \mathbf{q} \mid i\left(\mathcal{L}\left(\mathcal{M}_{n}(\delta \mathbf{q})\right)\right) \cap i\left(\mathcal{L}\left(\mathcal{B}_{n}\right)\right)=\emptyset\right\}
$$

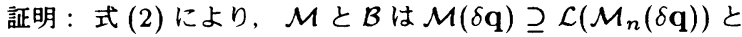
$\mathcal{B} \supseteq \mathcal{L}\left(\mathcal{B}_{n}\right)$ を満たす. $i(\mathcal{M}(\delta \mathbf{q})) \supseteq i\left(\mathcal{L}\left(\mathcal{M}_{n}(\delta \mathbf{q})\right)\right)$ および $i(\mathcal{B}) \supseteq i\left(\mathcal{L}\left(\mathcal{B}_{n}\right)\right)$ が成り立つので, $i\left(\mathcal{L}\left(\mathcal{M}_{n}(\delta \mathbf{q})\right)\right) \cap i\left(\mathcal{L}\left(\mathcal{B}_{n}\right)\right) \neq$ $\emptyset$ であるような配位では， $\mathcal{M}(\delta \mathbf{q})$ と $\mathcal{B}$ は常に交差する.し たがって $\mathcal{M}$ と $\mathcal{B}$ が非相貫条件を満たすためには， $\delta \mathbf{q}$ は $\mathcal{S}_{n i}=\left\{\delta \mathbf{q} \mid i\left(\mathcal{L}\left(\mathcal{M}_{n}(\delta \mathbf{q})\right)\right) \cap i\left(\mathcal{L}\left(\mathcal{B}_{n}\right)\right)=\emptyset\right\}$ に含まれる必要 がある.

条件 $2 \mathcal{M}$ と $\mathcal{B}$ の $k$ 組の実曲面 $\left\{G_{\mathcal{M} i}(\delta \mathbf{q}), G_{\mathcal{B}_{i}}\right\}, i \in[1, k]$ が 接触を実現するためには， $\delta \mathbf{q}$ は以下のように定義される変位べク トルの部分空間 $\mathcal{S}_{c}$ に含まれる必要がある ;

$$
\mathcal{S}_{c}=\left\{\delta \mathbf{q} \mid \forall i \in[1, k], \mathcal{T}\left(F_{\mathcal{M}_{i}}(\delta \mathbf{q})\right) \cap \mathcal{T}\left(F_{\mathcal{B}_{i}}\right) \neq \emptyset\right\}
$$

証明：式 (1)により， $\mathcal{M}$ と $\mathcal{B}$ の実曲面 $G_{\mathcal{M} i}$ と $G_{\mathcal{B} j}$ は $G_{\mathcal{M i}}(\delta \mathbf{q}) \subseteq \mathcal{T}\left(F_{\mathcal{M i}}(\delta \mathbf{q})\right)$ および $G_{\mathcal{B} j} \subseteq \mathcal{T}\left(F_{\mathcal{B}_{j}}\right)$ を满たすの で, $G_{\mathcal{M i}}(\delta \mathbf{q})$ と $G_{\mathcal{B}_{i}}$ が接的するためには，対応する面の公差域力洨差 すること, すなわち $\mathcal{T}\left(F_{\mathcal{M i}}(\delta \mathbf{q})\right) \cap \mathcal{T}\left(F_{\mathcal{B}_{i}}\right) \neq \emptyset$ が成り立つ必要があ る. したがって $k$ 組の実曲面 $\left\{G_{\mathcal{M}_{i}}(\delta \mathbf{q}), G_{\mathcal{B}_{i}}\right\}, i \in[1, k]$ が接触を 実現するためには， $\delta \mathbf{q}$ は $\mathcal{S}_{c}=\left\{\delta \mathbf{q} \mid \forall i \in[1, k], \mathcal{T}\left(F_{\mathcal{M i}}(\delta \mathbf{q})\right) \cap\right.$ $\left.\mathcal{T}\left(F_{\mathcal{B}_{i}}\right) \neq \emptyset\right\}$ に含まれる必要がある

条件 $3 \delta \mathbf{q}_{\text {min }}$ を，以下に示すような変位ベクトルの部分空間 $\mathcal{S}_{N I}$ 中で, 部品の位置決めに関する目的関数 $f(\delta \mathbf{q})$ を最小化する ベクトルとする；

$$
\mathcal{S}_{N I}=\left\{\delta \mathbf{q} \mid i\left(\mathcal{M}\left(\mathcal{M}_{n}(\delta \mathbf{q})\right)\right) \cap i\left(\mathcal{M}\left(\mathcal{B}_{n}\right)\right)=\emptyset\right\}
$$

$\mathcal{M}$ とB が最適化条件を満たすためには， $\delta \mathbf{q}$ は以下のように定義 される変位ベクトルの部分空間 $\mathcal{S}_{0}$ に含まれる必要がある;

$$
\delta \mathbf{q} \in \mathcal{S}_{o}=\left\{\delta \mathbf{q} \mid f(\mathbf{q}) \leq f\left(\delta \mathbf{q}_{\min }\right)\right\}
$$

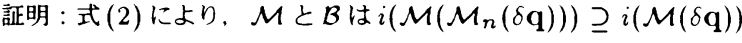
と $i\left(\mathcal{M}\left(\mathcal{B}_{n}\right)\right) \supseteq i(\mathcal{B})$ を満たすので, $i\left(\mathcal{M}\left(\mathcal{M}_{n}(\delta \mathbf{q})\right)\right) \cap$ $i\left(\mathcal{M}\left(\mathcal{B}_{n}\right)\right)=\emptyset$ であるような配位では， $\mathcal{M}(\delta \mathbf{q})$ と $\mathcal{B}$ は互いに他 方の内部へ食い込むことはない. ゆえに理想立体 $\mathcal{M}_{n}$ と $\mathcal{B}_{n}$ は, $\mathcal{S}_{N I}=\left\{\delta \mathbf{q} \mid i\left(\mathcal{M}\left(\mathcal{M}_{n}(\delta \mathbf{q})\right)\right) \cap i\left(\mathcal{M}\left(\mathcal{B}_{n}\right)\right)=\emptyset\right\}$ 内の任意の配 位を取れる.

$\delta \mathbf{q}_{\min }$ を, $\mathcal{S}_{N I}$ 中で目的関数 $f(\delta \mathbf{q})$ を最小化する変位べクト ルとする． $\delta \mathbf{q}$ の粠成する空間全体を $\mathcal{C}$ とすれば， $\mathcal{C} \supseteq \mathcal{S}_{N I}$ なの で, $\mathcal{C}$ 中には $f(\delta \mathbf{q}) \leq z\left(\delta \mathbf{q}_{\min }\right)$ を满たす変位ペクトル $\delta \mathbf{q}$ が必

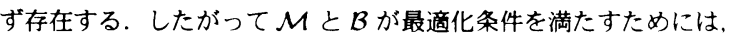
$\delta \mathbf{q}$ は $\mathcal{S}_{o}=\left\{\delta \mathbf{q} \mid f(\delta \mathbf{q}) \leq f\left(\delta \mathbf{q}_{\min }\right)\right\}$ に含まれる必要がある. 、

以上の 3 条件により，公差が許容する実立体が適切な組立てを実 現するためには，理想立体 $\mathcal{M}_{n}$ と $\mathcal{B}_{n}$ の配位を表す変位ベクトル $\delta \mathbf{q}$ は, $\mathcal{S}_{n i}, \mathcal{S}_{c}, \mathcal{S}_{o}$ の積に相当する空間に含まれる必要がある.

\section{4. 公差解析アルコリスム}

上述の理論により， $\mathcal{S}_{n i} \cap \mathcal{S}_{c} \cap \mathcal{S}_{o}$ を算出すれば，組立てられ た 2 部品の公差に起因する位置姿熬の変動篹囲が解析できる，そこ で $\mathcal{S}_{n i} \cap \mathcal{S}_{c} \cap \mathcal{S}_{o}$ を，変位べクトル $\delta \mathbf{q}$ に関する幾つかの凸領域 の和の形で算出するアルコリズムを開発した．

\section{1 処理のながれ}

このアルゴリズムは，解析対象の部品に関して以下の性質を仮定 する.

(1) 部品形状は多面体

（2）各面に定義された公差域も多面体形状

したがって公差の許容する最大実体状態と最小実体状態の立体も多 面体となる.

以下にアルゴリズムの処理のながれを示す

Step 1： 変位ベクトルの部分空間 $\mathcal{S}_{n i}=\left\{\delta \mathbf{q} \mid i\left(\mathcal{L}\left(\mathcal{M}_{n}(\delta \mathbf{q})\right)\right) \cap\right.$ $\left.i\left(\mathcal{L}\left(\mathcal{B}_{n}\right)\right)=\emptyset\right\}$ を算出する.

Step 2: $\quad \mathcal{S}_{c}=\left\{\delta \mathbf{q} \mid \forall i \in[1, k], \mathcal{T}\left(F_{\mathcal{M i}_{i}}(\delta \mathbf{q})\right) \cap \mathcal{T}\left(F_{\mathcal{B}_{i}}\right) \neq\right.$ $\emptyset\}$ を算出する.

Step 3: $\mathcal{S}_{N I}=\left\{\delta \mathbf{q} \mid i\left(\mathcal{M}\left(\mathcal{M}_{n}(\delta \mathbf{q})\right)\right) \cap i\left(\mathcal{M}\left(\mathcal{B}_{n}\right)\right)=\emptyset\right\}$ を算出する.

Step 4： $\mathcal{S}_{N I}$ において, 線形の目的関数 $f(\delta \mathbf{q})$ を最小化する 変位ベクトル $\delta \mathbf{q}_{\min }$ を算出する.

Step 5: $\mathcal{S}_{o}=\left\{\delta \mathbf{q} \mid f(\delta \mathbf{q}) \leq f\left(\delta \mathbf{q}_{\text {min }}\right)\right\}$ を算出する.

Step 6: $\mathcal{S}_{n i}, \mathcal{S}_{c}, \mathcal{S}_{o}$ の積を算出する

$\delta \mathbf{q}$ は公差に起因する部品の変位を表しており，通常ごく微小で ある.この性質を適切に利用すると， $\mathcal{S}_{n i}$ と $\mathcal{S}_{N I}$ を， $\delta \mathbf{q}$ に関 する幾つかの線形不等式の解の共通部分が定める凸領域として導 出できる．またStep 2 で計算される $\mathcal{S}_{c}$ は， $\delta q$ に関する線形 不等式群の解の和集合が定める幾つかの領域の積となる． $\mathcal{S}_{N I}$ が線形不等式の積集合であることから，Step 4 は， $\mathcal{S}_{N I}$ 中て $f(\delta \mathbf{q})$ を最小化する $\delta \mathbf{q}_{m i n}$ を，線形計画法を用いて探索すること で実現できる. Step 5 で定義される $\mathcal{S}_{0}$ は，明らかに線形不等式 $f(\delta \mathbf{q}) \leq f\left(\delta \mathbf{q}_{\text {min }}\right)$ の定める半空間である.

以上をまとめると， $\mathcal{S}_{n i} \cap \mathcal{S}_{c} \cap \mathcal{S}_{o}$ は，楾形不等式の積集合が 定める凸領域 $\mathcal{S}_{n i}$ と，線形不等式の和集合の定める領域の積 $\mathcal{S}_{c}$ と，半空間 $\mathcal{S}_{o}$ の稳となる. これは集合の論理式を適切に操作する ことで， $\delta \mathbf{q}$ に関する幾つかの線形不等式の栍集合の定める凸領域 の和へ変形できる，以後の節では，特に $\mathcal{S}_{n i}$ の計算法と $\mathcal{S}_{c}$ の計算 法について解説する． $\mathcal{S}_{N I}$ は $\mathcal{S}_{n i}$ と同じ方法で計算できる． $\mathcal{S}_{o}$ の計算法は以上の記述から明らかであろう。 


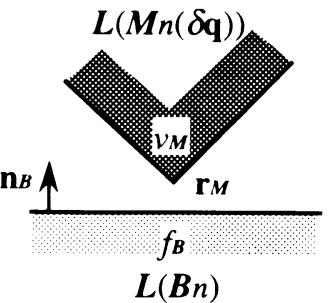

(a)

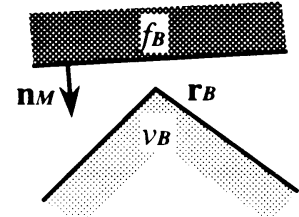

(b)
Fig. 4 Possible penetrations between two polyhedrons $\mathcal{L}\left(\mathcal{M}_{n}(\delta \mathbf{q})\right)$ and $\mathcal{L}\left(\mathcal{B}_{n}\right)$

\section{$4.2 \mathcal{S}_{n i}$ の}

$\mathcal{S}_{n i}=\left\{\delta \mathbf{q} \mid i\left(\mathcal{L}\left(\mathcal{M}_{n}(\delta \mathbf{q})\right)\right) \cap i\left(\mathcal{L}\left(\mathcal{B}_{n}\right)\right)=\emptyset\right\}$ は, 二つの多 面体 $\mathcal{L}\left(\mathcal{M}_{n}(\delta \mathbf{q})\right)$ と $\mathcal{L}\left(\mathcal{B}_{n}\right)$ が，互いに他方の内部へ食い込まな いような変位ベクトル $\delta \mathbf{q}$ の集合である. 二つの多面体間に生じ得 る接触として，片方の頂点と他方の面の点接触のみを仮定すると， $\mathcal{L}\left(\mathcal{M}_{n}(\delta \mathbf{q})\right)$ と $\mathcal{L}\left(\mathcal{B}_{n}\right)$ が相互に非侵入であるためには, 以下の 2 条件が満たされていればよい5);

(1) $\mathcal{L}\left(\mathcal{M}_{n}(\delta \mathbf{q})\right)$ の頂点が $\mathcal{L}\left(\mathcal{B}_{n}\right)$ の面の内側へ侵入しない.

(2) $\mathcal{L}\left(\mathcal{B}_{n}\right)$ の頂点が $\mathcal{L}\left(\mathcal{M}_{n}(\delta \mathbf{q})\right)$ の面の内側へ侵入しない.

変位ベクトルの大きさ $|\delta \mathbf{q}|$ を十分に小さな值に制限すると，配 位の変化にともなう頂点や面の移動をごく狭い範囲に抑えることが できるので ${ }^{11)}$ ，頂点が侵入し得る面をあらかじめ特定できる，そ こで $\mathcal{L}\left(\mathcal{M}_{n}(\delta \mathbf{q})\right)$ の頂点 $v_{\mathcal{M}}$ が, $\mathcal{L}\left(\mathcal{B}_{n}\right)$ の面 $f_{\mathcal{B}}$ へ侵入し得る 場合を考える. 理想的な組立て状態（すなわち $\delta \mathbf{q}=\mathbf{0}$ ）における 頂点 $v_{\mathcal{M}}$ の位置を $\mathbf{r}_{\mathcal{M}}$ とし, 面 $f_{\mathcal{B}}$ の方程式を $\mathbf{n}_{\mathcal{B}} \cdot \mathbf{X}=d_{\mathcal{B}}$ と する. ただし $\mathbf{n}_{\mathcal{B}}$ は， $f_{\mathcal{B}}$ の法線方向を表す単位ベクトルである.

2 立体の配位が $\delta \mathbf{q}$ 変化したとき， $v_{\mathcal{M}}$ が $f_{\mathcal{B}}$ の内側入侵入しな いためには，2次以上の微小項の影辢を無視すれば，以下の線形不 等式が満たされていれば良い9）（図4（a）参照）；

$$
\mathbf{n}_{\mathcal{B}} \cdot\left(\mathbf{r}_{\mathcal{M}}+\delta \Theta \times \mathbf{r}_{\mathcal{M}}+\delta \mathbf{s}\right) \geq d_{\mathcal{B}}
$$

ただし $\delta \mathbf{s}$ は $\delta \mathbf{q}$ 中の位置の変動成分を表し， $\delta \Theta$ は姿勢の変動 成分を表す. すなわち $\delta \mathbf{s}=[\delta x, \delta y, \delta z], \delta \Theta=\left[\delta \theta_{x}, \delta \theta_{y}, \delta \theta_{z}\right]$ である.

同様に $\mathcal{L}\left(\mathcal{B}_{n}\right)$ の頂点 $v_{\mathcal{B}}$ が， $\mathcal{L}\left(\mathcal{M}_{n}(\delta \mathbf{q})\right)$ の面 $f_{\mathcal{M}}$ の内側へ 侵入しないためには，以下の線形不等式が満たされていれば良い （図 4（b）参照）；

$$
\mathbf{n}_{\mathcal{M}} \cdot\left(\mathbf{r}_{\mathcal{B}}-\delta \Theta \times \mathbf{r}_{\mathcal{B}}-\delta \mathbf{s}\right) \geq d_{\mathcal{M}}
$$

そこで $\mathcal{L}\left(\mathcal{M}_{n}(\delta \mathbf{q})\right)$ と $\mathcal{L}\left(\mathcal{B}_{n}\right)$ の全頂点と, その頂点が侵入し得 るすべての面の組について，上述した 2 種類の線形不等式を立て る. 各不等式の解は, $\delta \mathbf{q}$ の定める空間中の半空間に対応する. し たがってこれらの積集合の定める凸領域が $\mathcal{S}_{n i}$ となる.

\section{$4.3 \mathcal{S}_{c}$ の計算法}

$\mathcal{S}_{c}=\left\{\delta \mathbf{q} \mid \forall i \in[1, k], \mathcal{T}\left(F_{\mathcal{M i}}(\delta \mathbf{q})\right) \cap \mathcal{T}\left(F_{\mathcal{B}_{i}}\right) \neq \emptyset\right\}$ は, す べての対偶において，対偶を構成する二つの面の公差域 $\mathcal{T}\left(F_{\mathcal{M i}}(\delta \mathbf{q})\right)$ と $\mathcal{T}\left(F_{\mathcal{B}_{i}}\right)$ が交わりを持つような，変位ベクトル $\delta \mathbf{q}$ の集合 である.したがって各面の租について，変位ベクトルの集合 $\mathcal{S}_{c i}=\left\{\delta \mathbf{q} \mid \mathcal{T}\left(F_{\mathcal{M} i}(\delta \mathbf{q})\right) \cap \mathcal{T}\left(F_{\mathcal{B} i}\right) \neq \emptyset\right\}$ を計算し，それらの 積集合を求めればよい。
$\mathcal{S}_{c i}$ は, $\left\{\delta \mathbf{q} \mid i\left(\mathcal{T}\left(F_{\mathcal{M} i}(\delta \mathbf{q})\right)\right) \cap i\left(\mathcal{T}\left(F_{\mathcal{B} i}\right)\right)=\emptyset\right\}$, すなわち 二つの公差域が互いに他方の内部に侵入しないような変位ベクトル の集合を算出し，その補集合を正規化することで得られる．仮定か ら面の公差域は多面体領域なので，公差域が互いに非侵入であるよ うな変位ベクトルの集合は，4.2 節で述べた手法を用いることで, $\delta \mathbf{q}$ に関する線形不等式の解の積集合として表現できる．したがつ てその補集合を正規化した $\mathcal{S}_{c i}$ は，ド・モルカン則により線形不等 式の解の和集合となる. ゆえに $\mathcal{S}_{c}=\bigcap_{i} \mathcal{S}_{c i}$ は, 線形不等式群の 解の和集合が定める幾つかの領域の積となる.

\section{It 実}

$\mathrm{C}$ 言語を用いて公差解析プログラムを試作し，幾つかの計算実駼 をおこなった。

\section{1 多角形部品の公美解析}

手法の有効性をとりあえず評価するために，多面体ではなく，公 差が指示された二つの多角形からなる組立品の, 位置姿勢の暧昧さ を解析することにした．これは前節までの議論を，以下のように置 き換えたものに対応する.

（1）二つの平面図形の配位は，各図形の固有座標系の位置の違い を表すパラメータ $x, y$ と，姿势の違いを表すパラメータ $\theta_{z}$ によ り表現できる. したがって変位べクトルは $\delta \mathbf{q}=\left[\delta x, \delta y, \delta \theta_{z}\right]$ となる.

（2）公差域は多角形領域であり，多角形部品の各辺に指示され ている. したがって公差の許容する最大実体状態と最小実体状 態の図形も多角形となる.

（3）対偶は多角形の辺の接触関係として指示される.

（4）公差解析アルコリリズムは，二つの多角形が互いに他方の内 部へ侵入しないような変位ベクトルの部分空間を計算する問題 に帰着できる。

（5）多角形間の干渉は，一般に頂点と辺の衝突により生じる. 変位ベクトルの大きさを十分に微小と仮定すると, 頂点が他方 の図形の辺の内側へ侵入することを禁止する条件は， $\delta \mathbf{q}$ に関 する線形不等式により表現できる 6$)$.

\section{2 例题}

図 5 に, 計算実験で用いた二つの多角形 $\mathcal{M}_{n}$ と $\mathcal{B}_{n}$ を取り巻 <, 公差が許容する最大実体状態と最小実体状態の多角形を示す. これらの図形は, $\mathcal{M}_{n}$ と $\mathcal{B}_{n}$ の各辺を外側と内側へ 0.25 ずつオフ セットした図形に相当する. 図には示していないが, $\mathcal{M}_{n}$ と $\mathcal{B}_{n}$ の各辺には, 公差域が多角形領域として指示されている. 図中に指 示されている “=”記号は, 对偶を構成する辺の組を表している. それぞれの図形には, 固有の座標系をその原点が多角形の重心と 一致するように，また理想的な組立て状態では，二つの座標系の $y$ 軸の方向がともに上方を向くように与えた．部品を最適な位置姿勢 に配置するための目的関数として, $f(\delta \mathbf{q})=\delta y$ を用いた. した がって公差が許容する実部品のモデルは，その配位の $y$ の值ができ るだけ小さくなるように, 言い換えれば上側の部品ができるだけ下 方になるように配置される.

\section{3 解析結果}

解析結果を図6に示す．この図は，変位ベクトルの変動篹囲を表 す $\mathcal{S}_{n i} \cap \mathcal{S}_{c} \cap \mathcal{S}_{o}$ を, 変位ベクトルの構成する空間中の $\delta \theta_{z}-\delta x$ 平面へ投影した図形を示している.このような表示は，変動籍囲を 表す不等式の組合せに，CSG モテルのレンダリング手法を適用す ることで得られる. 図の横軸は生じ得る姿勢の変動節囲（単位はラ

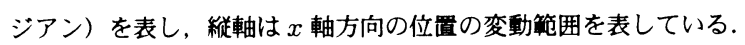




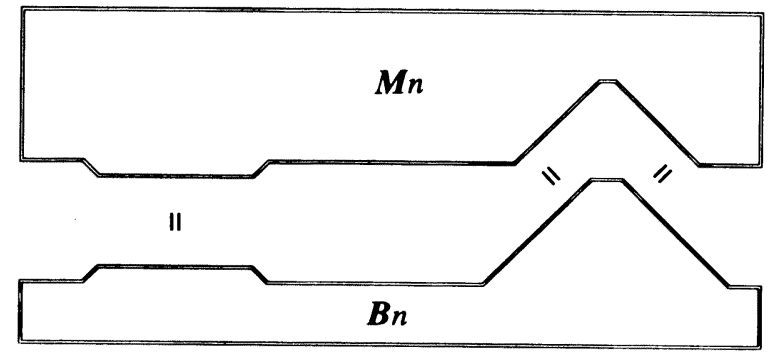

Fig.5 Maximum material polygons and least material polygons of the example polygonal assembly

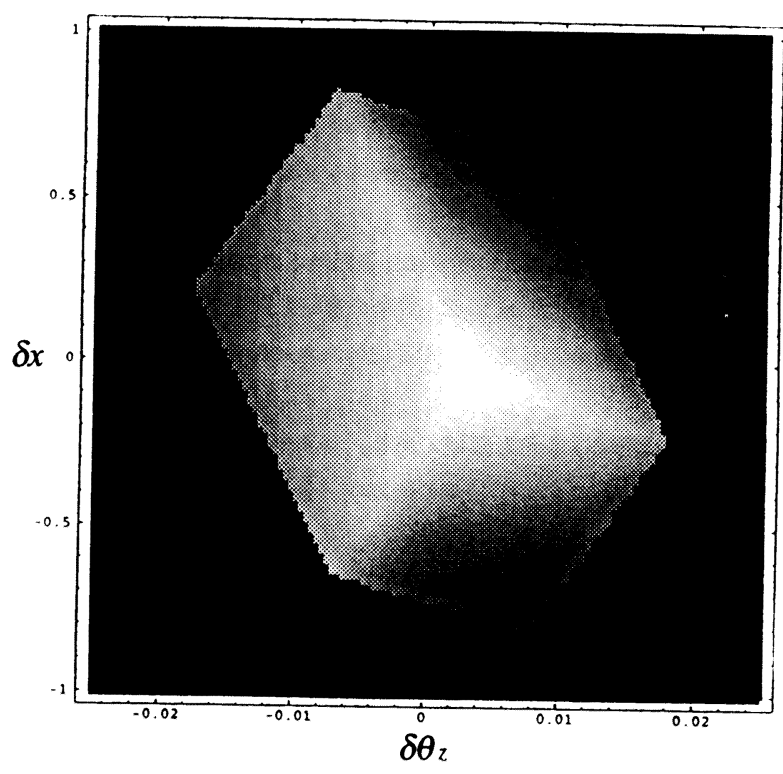

Fig.6 Derived bound of the configuration uncertainty of the example parts

また図中の濃淡は， $y$ 軸方向の位置の変動箸囲を表しており，薄い 色ほど変動量が大きいことを意味する。

図 7に, $\mathcal{S}_{n i} \cap \mathcal{S}_{c} \cap \mathcal{S}_{o}$ 内で最大の $\delta \theta_{z}$ 值に対応する図形の位 置姿勢と, 最小の $\delta \theta_{z}$ 值に対応する位置姿勢を示す。これらの計算 にはPC （CPU：Pentium 100MHz，主記憶：16MB）を用 いた．上記の例以外にも，幾つかの多角形の組立品に対して本プロ グラムを適用したが，いずれの場合にも妥当な結果が瞬時に得られ た.

\section{6. まとめと展 望}

本論文では，公差に起因する組立品の位置姿勢の暧昧さを，配位 空間を用いて解析する新しい手法を説明した．この手法は, 公差が 指示された 2 部品の配位空間中で, 公差が許容する実部品が非相貫 条件, 接触条件, 最適化条件を満足し得る部分空間を算出すること で公差解析をおこなう．公差に起因する位置姿勢の変動は，ごく微 小之考えられる.この性質を利用して，組立てられた二つの多面体 部品の相対的な位置姿勢の変動範囲を, 線形不等式の解の積集合が 定める幾つかの凸領域の和として算出する手法を開発した．また手 法の有効性を検証するために，2次元多角形からなる組立品の公差 解析をおこなうプログラムを作成し, 計算実験をおこなった. 現在 3次元多面体からなる組立品の, 公差解析をおこなうプログラムを

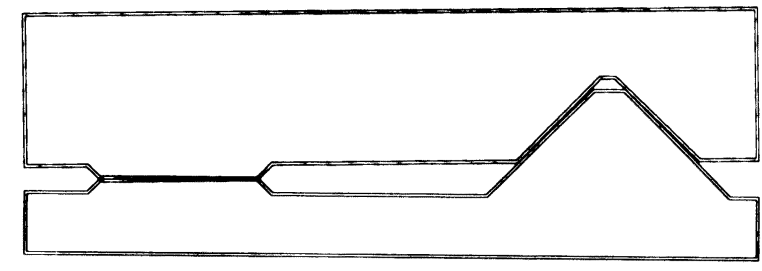

Maximum $\delta \theta_{z}$

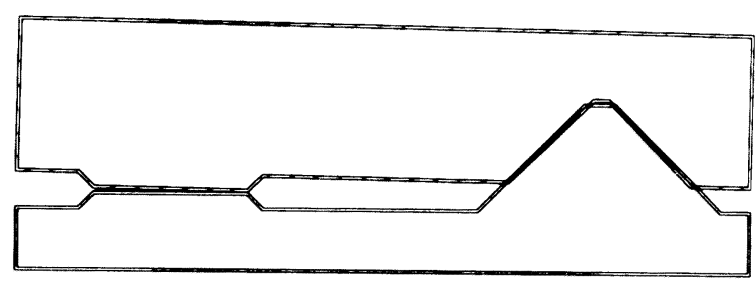

Minimum $\delta \theta_{z}$

Fig.7 Extreme configurations allowed in the bound

作成中である，また曲面を含む組立品を解析するために，手法の桩 張を検討している. 本研究は, 科学研究費補助金基盤研究 $(C)$ 課題 番号 08650307 を受けておこなわれた，関係者各位に感謝する．

\section{考文献}

1) A. Fleming: Analysis of Uncertainties and Geometric Tolerances in Assemblies of Parts, Ph.D. Thesis, University of Edinburgh, (1987).

2) M. Inui, M. Miura and F. Kimura: Analysis of Position Uncertainties of Parts in an Assembly Using Configuration Spaces in Octree Representation, Proc. ACM Symp. Solid Modeling and Applications, (1995) 73

3) M. Inui, M. Miura and F. Kimura: Positioning Conditions of Parts with Tolerances in an Assembly, Proc. IEEE Int. Conf. Robotics and Automation, (1996) 2202

4) ISO: Technical drawings - Geometrical tolerancing - Tolerances of form, orientation, location and runout - Generalities, definitions, symbols, indications on drawings, ISO 1101-1983, (1983).

5) L. Joskowicz and R. H. Taylor: Interference-Free Insertion of a Solid Body into a Cavity: An Algorithm and a Medical Application, Int. J. Robotics Res., 153, (1996) 211 .

6) 金田光広, 乾 正知: 微小な形状誤差を含む組立品の位羁決めア

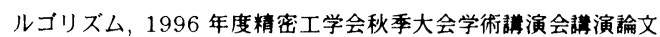
集, (1996) 585

7) A. A. G. Requicha: Toward a Theory of Geometric Tolerancing, Int. J. Robotics Res., 2-4, (1983) 45

8) R. Sodhi and J. U. Turner: Relative Positioning of Variational Part Models for Design Analysis, Computer-Aided Design, 26-5, (1994) 366

9）武田捷一，丸山稔，重井克之：物理法則に基づく剛体運動のシ ミュレーション手法, ダラフィクスと CAD 研究会資料, 73-4, (1995) 25.

10) J. U. Turner: Relative Positioning of Parts in Assemblies Using Mathematical Programming, ComputerAided Design, 22-7, (1990) 394.

11) J. Xiao: Automatic Determination of Topological Contacts in the Presence of Sensing Uncertainties, Proc. IEEE Int. Conf. Robotics and Automation, (1993) 65. 